\title{
Extortion or self-defence? - tempers rise in claims row
}

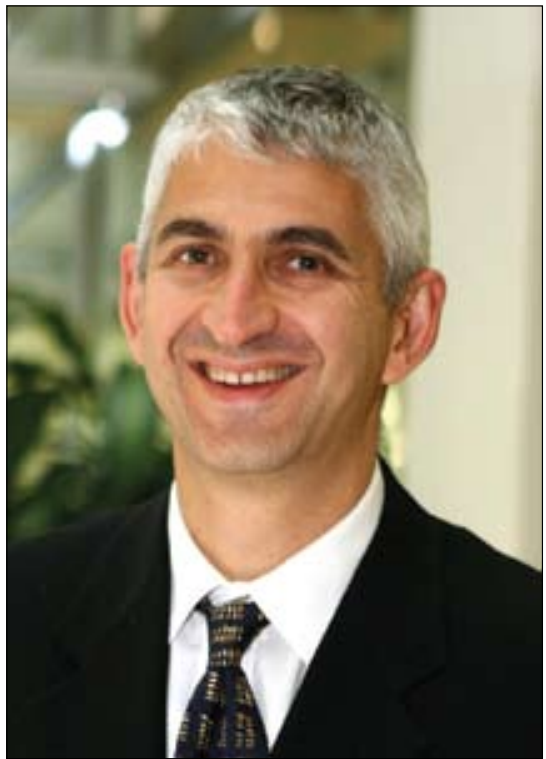

Jonathan Broomberg, deputy CEO of Discovery Health.

Are embattled medical aids indulging in bully-boy 'extortion' tactics or merely recouping losses from suspect health care practitioners whom the industry claims cost it R7 - R10 billion (10\% of payouts) in fraud, abuse or over-servicing every year?

The issue of suspect health care practitioners being pressured to sign once-off 'acknowledgement of debt' notes to avoid potentially ruinous criminal and business censure was brought centre-stage by the Health Professions Council of South Africa (HPCSA) last month.

Without naming anyone, it publicly slammed 'a large number of leading medical aids' for what it termed 'criminal extortion' or 'acting as debt collection agencies' whenever health care practitioners were suspected of over-servicing or fraud.

HPCSA spokesperson Bertha PetersScheepers said that over the 'last couple of months' the Council had received a surge of 'at least 20' complaints from aggrieved doctors. The South African Medical Association (SAMA) backed the HPCSA, saying that while it did not condone fraudulent activities, it had 'always been concerned' by the investigation ethics of schemes that so often soured doctor-patient relationships.

In what appeared to be a jealous guarding of its legislative territory, the HPCSA publicly condemned the 'unfair' practice of health care practitioners being confronted with untested evidence by medical aids at hastily called 'mediation meetings'.

\section{Debt notes 'inflated, thumb sucks' - HPCSA}

It said any refusal to sign 'inflated, thumb-suck' acknowledgements of debt (AODs) meant the matter was referred to the HPCSA, details being circulated via the Board of Healthcare Funders (BHF) (and included on its fraud database), criminal charges and the withholding of any monies owing to the practitioner by the relevant medical aid. Additionally, any subsequent claims were paid directly to the patient. 'This leaves the practitioner with no choice but to succumb to these unlawful acts that amount to nothing less than extortion,' the Council asserted. It put health care practitioners in potential 'double jeopardy' where they signed AODs and then had to face HPCSA professional conduct hearings. PetersScheepers said that in practice, however, medical schemes tended to 'only refer cases to us when practitioners refuse to sign AODs'.

over the 'last couple of
months' the Council had
received a surge of 'at
least $20^{\prime}$ ' complaints from
aggrieved doctors.

Proper practice would be to refer the matter to the HPCSA for resolution and seek a civil remedy for financial compensation. The HPCSA would be abdicating its responsibility to 'protect the public and guide the professions' if it did not offer protection from this 'unprofessional and criminal' conduct.

\section{BHF 'takes exception'}

Spokesperson for the BHF (official representative body for medical aid schemes), Heidi Kruger, took strong exception to the HPCSA's language. She said that far from acting illegally or unethically, medical schemes were legally obliged to act in the best interests of their members. Denying that the practice constituted 'prosecution', she said recouping money gained through fraudulent activities was no different than dealing with a case of shoplifting. 'Returning the item to the shop once the shoplifter has been caught hardly amounts to prosecution,' she added.

She was 'surprised' by the HPCSA's tone, given that when the BHF set up its Forensic Management Unit 'we worked with both the SAMA and the HPCSA on policies and procedures for investigation'. Contrary to one HPCSA claim, health care practitioners were allowed full representation at mediation meetings. Kruger appealed to the HPCSA's lawyers to cite wherever medical schemes had acted outside of the agreed-upon policies and procedures 'so we can bring them into line'. 'Also, we act based on legal precedent where a doctor tried to argue in court that if a scheme paid a member direct he'd go bankrupt ... when the Asset Forfeiture Unit takes your stuff they don't worry about whether you'll go into financial ruin,' she said. If a health care practitioner believed they had done nothing wrong, 'they won't sign an AOD,' she said, a point PetersScheepers strongly rebutted with: 'the facts speak to a lack of proper, fair procedure and coercion which we see as extortion'. Kruger said all medical aid schemes were obliged to report deviant health care practitioner behaviour to the HPCSA but claimed it took the Council ' 3 - 4 years' to reach the point of an actual hearing. The accused might eventually get a suspended sentence, be fined or pay admission of guilt fines, 'which are sometimes about R10 000 - when schemes have actually been defrauded of millions and that money 
goes to the HPCSA, not the medical aid,' she said pointedly.

\section{Schemes 'can't give us proof of quantum' - HPCSA}

While confirming this, Peters-Scheepers said the Health Professions Act enabled her Council's committee of enquiry to order financial restitution - although medical schemes were seldom able to 'provide us with scientific proof of quantum'.

\begin{tabular}{c}
\hline It put health care \\
practitioners in potential \\
'double jeopardy' where they \\
signed AODs and then had \\
to face HPCSA professional \\
conduct hearings.
\end{tabular}

Her senior legal manager, Advocate Tshepo Boikanyo, had proposed ring-fencing medical aid fraud with a special committee to fast track such cases to protect both the schemes and practitioners, but schemes had shown little enthusiasm

Currently, the fines the HPCSA could levy 'don't even cover our legal costs', but proposed legislation upped the minimum fine for over-servicing to R20 000 (or the amount over-serviced plus $5 \%$ of such amount), and a minimum of R20 000 and a maximum of R70 000 for fraud convictions. Kruger said the BHF 'conservatively' estimated annual losses to fraud, systemic abuse and over-servicing at between R7 and R10 billion.

\section{'The courts back us' - Discovery}

Jonathan Broomberg, deputy CEO of Discovery Health, said his company never took action 'until we're very confident that the evidence we've accumulated is water tight and will stand up in a court of law'. Recovery of monies inappropriately paid out as a result of fraud or abuse was a 'critical role' carried out by medical schemes that were responsible to contributing members and to ensuring the sustainability of the industry. Abuse needed to be 'decisively' dealt with

Broomberg cited a 2005 Supreme Court of Appeal ruling upholding the right of medical schemes to 'engage' with suspect practitioners and deeming such interactions 'not to represent extortion or duress, but legitimate commercial interactions'. Discovery Health never insisted on settlement occurring during the initial meeting and always allowed time for further investigation and responses by the practitioner. The HPCSA had many times requested Discovery to ensure all such cases were reported to them. Reporting suspect practitioners to the police and the HPCSA was 'neither threat nor extortion, but obligations we have to honour'. Medical schemes were entirely within their rights in paying funds directly to members. He echoed Kruger in complaining about lengthy HPCSA disciplinary processes.

\section{HPCSA 'marble polishing'?}

The forensic manager of a medical scheme who insisted on remaining anonymous, said the HPCSA's emotive language was 'part of a marblepolishing exercise' aimed at health care practitioners, the majority of whom felt historical animosity towards it.

'They're trying to show that they add value to doctors, instead of just taking your fees annually, bumping you off the register for late annual fee payment or prosecuting you for striking in frustration in the occupation-specific dispensation controversy,' he added.

Another argued, 'We're trying to change (practitioner) behaviour here. We want to try and keep the guy in practice and make a positive contribution to the industry. We have a shortage of doctors in South Africa so we need to be responsible in the way we deal with it.' He added, 'This just makes our job harder. The guys now think they have the backing of the HPCSA.' The HPCSA issued a similar warning to medical schemes several years ago but said the sudden increase in doctor complaints this year prompted a repeat. This year's warning accompanied the release of its annual disciplinary hearing statistics. These show that 12 of 13 health care practitioners charged have been found guilty of over-servicing, fraud, and overcharging so far this year, versus 36 of 46 charged found guilty on similar charges last year - hardly a stemming of the financial haemorrhage cited by medical aid schemes.

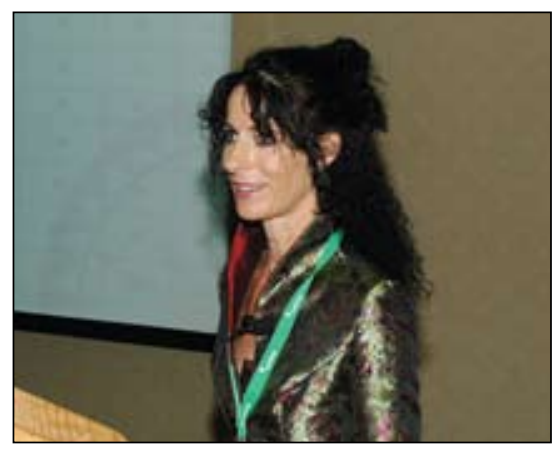

Heidi Kruger, corporate communications officer for the Board of Healthcare Funders.

Picture: Chris Bateman

This year 1 practitioner was fined and 8 were suspended (for claiming for services not rendered). Last year 2 were erased from their professional registers, a dozen fined, and 3 fined and suspended (for claiming for services not rendered). Penalties ranged from admission of guilt fines of R5 000 to R15 000, through 3 years suspension from the register (conditionally suspended for 5 years), to full erasure. Peters-Scheepers said cases that took several years to finalise were 'the exception not the rule,' adding that on average it took 18 months from the time a formal HPCSA enquiry began until it was concluded.

'We're trying to change
(practitioner) behaviour
here. We want to try and keep the guy in practice and make a positive contribution

to the industry. We have a shortage of doctors in South

Africa so we need to be responsible in the way we deal with it.'

\section{Schemes regulator mystified}

Spokesperson for the Council for Medical Schemes (the official scheme's regulator), Aleksandra Serwa, said they had received 'not a single (extortion or harassment) complaint' from doctors but were 'engaging with the HPCSA'. 'As the regulator we need to know if schemes are breaking the law but it's up to the HPCSA whether it refers cases on to us - they haven't done so,' she added. 'Once we have something concrete we'll issue a statement,' she said.

\section{Chris Bateman}

